\title{
Feeding of Fragilidium cf. duplocampanaeforme and F. subglobosum on four Dinophysis species: prey specificity, local adaptation and fate of toxins
}

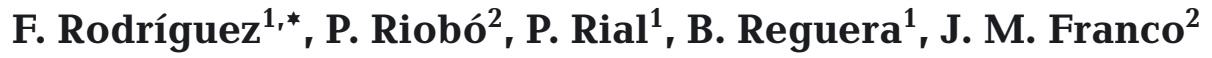 \\ ${ }^{1}$ Instituto Español de Oceanografia (IEO), Centro Oceanográfico de Vigo (UA Fitoplancton Tóxico CSIC-IEO), \\ Subida a Radio Faro 50-52, Cabo Estay, Canido, 36390 Vigo, Spain \\ ${ }^{2}$ Instituto de Investigaciones Marinas, CSIC (UA Fitoplancton Tóxico CSIC-IEO), Eduardo Cabello, 6, 36208 Vigo, Spain
}

\begin{abstract}
We studied the feeding behaviour of 2 Fragilidium species $-F$. cf. duplocampanaeforme (strains VGO1120 and VGO692 from NW Iberia and the Mediterranean Sea, respectively), and F. subglobosum (IO97-01, W Iberia) - on Dinophysis acuminata, D. acuta, D. caudata and D. tripos from NW Iberia. Only the Atlantic strain of F. cf. duplocampanaeforme fed upon D. acuminata $\left(2.52 \pm 0.48\right.$ cells Fragilidium $\left.{ }^{-1} \mathrm{~d}^{-1}\right)$ and D. caudata $\left(0.58 \pm 0.32\right.$ cells Fragilidium $\left.{ }^{-1} \mathrm{~d}^{-1}\right)$; furthermore, this strain fed weakly on $D$. tripos $\left(<0.10\right.$ cells Fragilidium ${ }^{-1} \mathrm{~d}^{-1}$ ) and not at all on $D$. acuta. Neither the Mediterranean F. duplocampanaeforme nor F. subglobosum were observed to ingest Atlantic strains of Dinophysis species. Deleterious effects caused by Fragilidium, namely cell immobilization or even death, were observed in some cases (the D. acuminata and D. caudata cultures). The Atlantic $F$. cf. duplocampanaeforme that had previously fed on $D$. acuminata and $D$. caudata showed low intracellular toxin levels at the end of the exponential growth phase (based on LC-MS). However, extracellular toxin levels were higher in the Dinophysis cultures exposed to the Atlantic F. cf. duplocampanaeforme than in those without Fragilidium (the contrary being true for the toxin amount per cell). Our results indicate that (1) Fragilidium cf. duplocampanaeforme feeds differentially on certain Dinophysis species (in particular D. acuminata and D. caudata), (2) inter-specific and intraspecific differences exist in Fragilidium-Dinophysis predator-prey interactions, (3) the amount of extracellular Dinophysis toxins is enhanced by the presence of Fragilidium, and (4) decreased final yields and higher frequencies of small cells of Fragilidium in mixotrophic cultures.
\end{abstract}

KEY WORDS: Dinophysis - Fragilidium - Prey specificity · Okadaic acid · DSP toxins transfer · Mixotrophy Resale or republication not permitted without written consent of the publisher

\section{INTRODUCTION}

Dinoflagellates are marine protists which include photosynthetic and heterotrophic species but also many mixotrophic species that may take up nutrients through phototrophic and phagotrophic behaviour (Stoecker et al. 2006). Mixotrophy can be obligatory, as it is for those Dinophysis species that need to 'steal' plastids periodically from the ciliate Meso- dinium rubrum (Park et al. 2006). However, in many cases, mixotrophic dinoflagellates contain constitutive plastids and maximize their growth rates when ingesting other algae (Stoecker 1999, Jakobsen et al. 2000, Jeong et al. 2005). Mixotrophic dinoflagellates can be found in most taxonomic orders, e.g. Gymnodiniales, Prorocentrales, Dinophysiales, Gonyaulacales, Blastodiniales, Peridiniales and Noctilucales (Stoecker 1999). 
Fragilidium is a facultative mixotrophic dinoflagellate genus, with 6 species described to date: F. fissile, $F$. duplocampanaeforme, F. heterolobum, F. lacustre, F. mexicanum and F. subglobosum (Lindemann 1924, Balech 1959, von Stoch 1969, Balech 1987, 1990, Nézan \& Chomérat 2009). The mixotrophic nature of most Fragilidium species has been already reported (Skovgaard 1996, Jeong et al. 1999, Park \& Kim 2010). According to these authors, Fragilidium feeds only on dinoflagellates, but different levels of prey selectivity have been observed for each species. Thus, F. subglobosum have been reported to feed only on Ceratium spp. and F. duplocampanaeforme on Dinophysis spp. (Park \& Kim 2010, Hansen 2011), although a recent study (Amorim et al. 2013) described the predation of F. subglobosum and F. cf. duplocampanaeforme from Portuguese coastal waters on Ceratium horridum. In turn, F. mexicanum has been shown to feed on multiple dinoflagellate genera, such as Akashiwo, Alexandrium, Ceratium, Lingulodinium, Prorocentrum, Protoperidinium and Scrippsiella (Jeong et al. 1999). Furthermore, Fragilidium growth responds in different ways depending on its prey. For example, $C$. tripos has been reported to be a more suitable prey for $F$. subglobosum than $C$. furca and C. fusus (Hansen \& Nielsen 1997).

Recently, Park \& Kim (2010) described the prey specificity and feeding mechanism of Fragilidium duplocampanaeforme isolated from Masan Bay (South Korea). Based on a previous report of F. duplocampanaeforme containing D. acuminata and D. caudata from the French Atlantic coast, Nézan \& Chomérat (2009) demonstrated that their isolate fed exclusively on Dinophysis when different dinoflagellates were offered as prey. These authors tested 4 species of Dinophysis: D. acuminata, D. caudata, D. fortii and D. infundibulus, from the same location as their strain of F. duplocampanaeforme. All Dinophysis species, except $D$. fortii, were ingested by Fragilidium, and deleterious effects on Dinophysis (motility decrease) were observed in all cases.

Shellfish harvesting closures due to contamination with diarrheic shellfish poisoning (DSP) toxins above regulatory levels are commonplace in the Galician Rías (NW Iberian Peninsula). Toxic outbreaks are associated with the occurrence of Dinophysis species, mainly $D$. acuminata but also $D$. acuta and $D$. caudata. In fact, D. acuminata, D. sacculus, D. ovum, D. acuta, D. fortii and D. caudata are common Dinophysis species in warm temperate seas (Reguera et al. 2012). Toxin profiles and cellular content are highly variable between Dinophysis species (and between strains of the same species), but all the aforementioned are known to produce okadaates (okadaic acid [OA] and its congeners the dinophysistoxins [DTXs]) and/or pectenotoxins (PTXs) (reviewed by Reguera et al. 2014). The term 'Dinophysis toxins' (DsT) will be used throughout to indicate the sum of okadaates and PTXs produced by Dinophysis species.

Fragilidium species are common in Galician waters and can be easily recognized when forming ecdysal cysts. The presence of $F$. cf. duplocampanaeforme and F. subglobosum in the NW Iberian Peninsula was reported in a recent study (Amorim et al. 2013). However, to our knowledge, there are no studies on Fragilidium abundance, diversity and feeding behavior on Dinophysis spp. or on any other dinoflagellates in that area.

In the present study, we focused on the feeding behavior of 2 strains of Fragilidium cf. duplocampanaeforme (hereafter referred to as the Atlantic and Mediterranean Fragilidium) and 1 strain of F. subglobosum IO97-01 (W Iberia) on 4 Dinophysis species (D. acuminata, D. acuta, D. caudata and D. tripos). The potential impact of the Atlantic Fragilidium on Dinophysis is discussed on the basis of estimated grazing rates in the laboratory. DsT were also analysed in the Atlantic Fragilidium cells and culture filtrate to follow the fate of these compounds whenever Dinophysis spp. were exposed to and eventually ingested by the Atlantic Fragilidium.

\section{MATERIALS AND METHODS}

\section{Cultures}

Four Dinophysis species were isolated from the Galician Rías, NW Iberian Peninsula (Fig. 1), and established in mixotrophic cultures with their ciliate prey: D. tripos VGO1062 and D. acuminata VGO1063 (October 2009, Stn B1, Ría de Vigo, 42²1.40’ N $8^{\circ} 46.42^{\prime} \mathrm{W}$ ), D. caudata VGO1064 (April 2010, Stn P2, Ría de Pontevedra, $42^{\circ} 8.22^{\prime} \mathrm{N}, 8^{\circ} 51.36^{\prime} \mathrm{W}$ ) and $D$. acuta VGO1065 (October 2010, Stn P2). Strains of the ciliate Mesodinium rubrum (AND-A0711) and the cryptophyte Teleaulax amphioxeia (AND-A0710), added periodically to the ciliate cultures as prey, were both isolated in 2007 in the course of weekly sampling of the Andalusian Monitoring Programme (Huelva, SW Spain). Cultures of Fragilidium subglobosum (IO97-01, Fig. 2A) were established by isolation of single cells from plankton-net haul samples in Portuguese coastal waters (Amorim et al. 2013). Fragilidium cf. duplocampanaeforme (Fig. 2B,C) were 


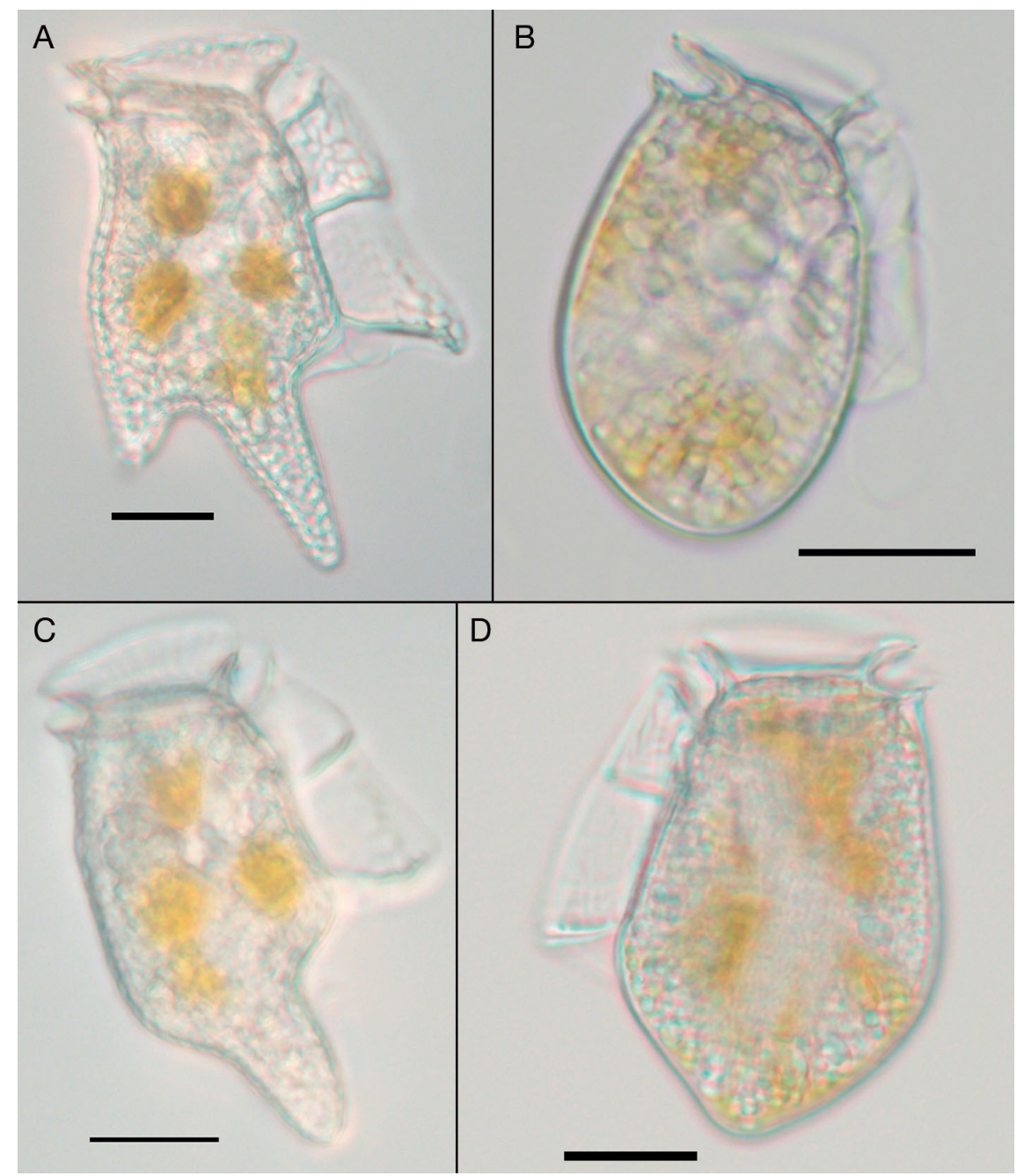

Fig. 1. Light micrographs (live cells) of the Dinophysis strains used in this study: (A) D. tripos, (B) D. acuminata, (C) D. caudata, (D) D. acuta. Scale bars $=20 \mu \mathrm{m}$

isolated during opportunistic samplings at Ría de Vigo (VGO 1120, Stn B1, July 2009) and Elefsis Bay, Saronikos Gulf, Greece (VGO 692, July 2003). Both isolates were genetically characterized by Amorim et al. (2013), and their morphologies matched that of $F$. duplocampanaeforme (Nézan \& Chomérat 2009), but the lack of molecular data from the type locality led us to label these strains as F. cf. duplocampanaeforme. All cultures were grown in diluted (1/20) L1Si medium at $19^{\circ} \mathrm{C}, 32 \mathrm{psu}$, under a $12 \mathrm{~h}$ light: $12 \mathrm{~h}$ dark cycle with $150 \mu \mathrm{mol}$ photons $\mathrm{m}^{2} \mathrm{~s}^{-1}$ irradiance.

\section{Feeding experiments}

Three replicate cultures of the Atlantic Fragilidium and each of the 4 Dinophysis species were mixed in $50 \mathrm{ml}$ glass flasks at an approximate initial concentration of 100 and 300 cells ml ${ }^{-1}$, respectively. Cell counts were carried out using Sedgewick-Rafter chambers under a light microscope. The same approach was used for the Mediterranean Fragilidium and $F$. subglobosum, but mixed cultures were incubated in 24 well microplates (Thermo Scientific). Specific growth rates $\left(r, t^{-1}\right)$ were calculated as follows:

$$
r=\ln (\mathrm{Nt} / \mathrm{N} 0) / \delta t
$$

In the case of the Atlantic Fragilidium, 2 size classes typically described in Dinophysis spp. (normal vegetative and small forms) were distinguished and enumerated. The ingestion rates $(I=$ Dinophysis cells eaten Fragilidium ${ }^{-1} \mathrm{~d}^{-1}$ ) were calculated following Eqs. (2-4) as described by (Frost 1972): 

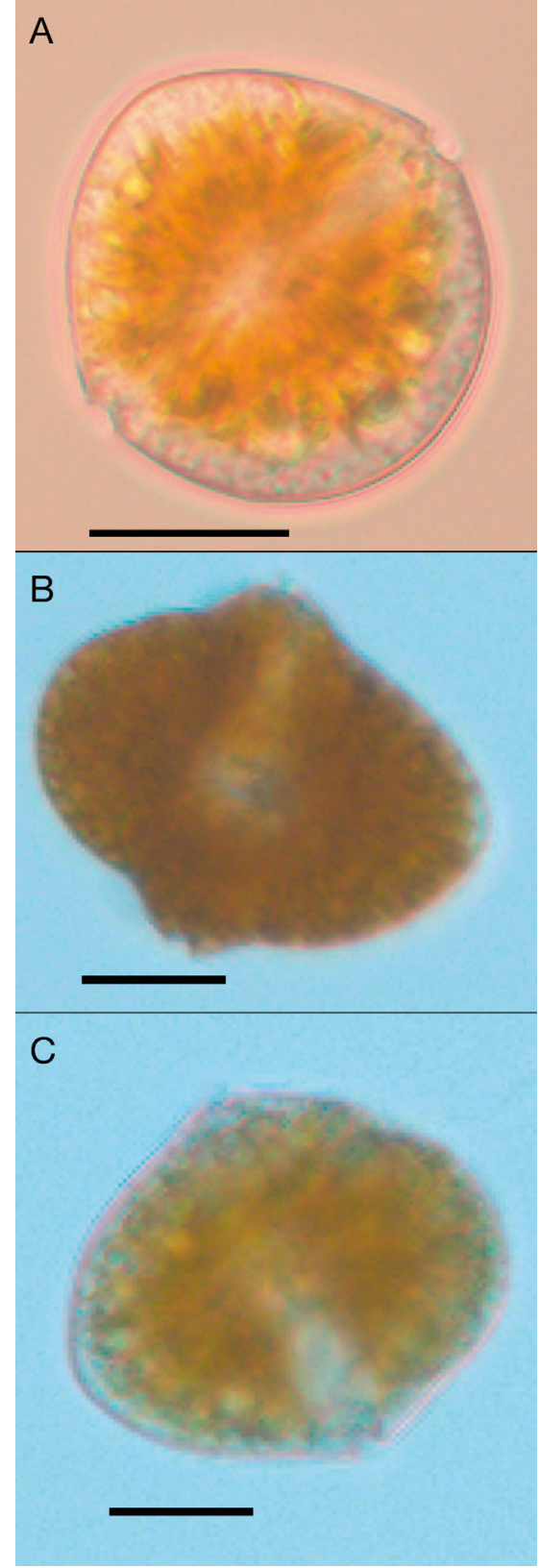

Fig. 2. Light micrographs (live vegetative cells) of the Fragilidium strains used in this study. (A) F. subglobosum, (B) Atlantic Fragilidium, (C) Mediterranean Fragilidium. Scale bars $=20 \mu \mathrm{m}$

$$
C=C_{1} \times\left[\mathrm{e}^{(r-g)\left(t^{2}-t^{1}\right)}-1\right] /\left(t_{2}-t_{1}\right)(r-g)
$$

where $C_{1}$ is the Dinophysis cell concentration at $t_{1}, r$ is the specific growth rate for Dinophysis, $g$ is the grazing coefficient, and $C$ is the average cell concentration of Dinophysis during a time interval $\left(t_{2}-t_{1}\right)$;

$$
F=V g / N
$$

where $F$ is the volume swept clear (volume of ambi- ent medium from which the cells are completely removed by Fragilidium to achieve the measured ingestion rate), $V$ is the volume (ml) of the cultures, and $N$ is the average number (cells) of Fragilidium; and

$$
I=C \times F
$$

\section{Allelopathy experiments}

Effect on Dinophysis species of exposure to Atlantic Fragilidium cf. duplocampanaeforme cells

In total, $0.2 \mathrm{ml}$ of the Atlantic Fragilidium culture in exponential growth phase were added to D. acuminata, D. acuta and D. caudata cultures ( $2 \mathrm{ml}$ volume at 300 cells ml ${ }^{-1}$ ) in 24 well plates (Thermo Scientific). The predator:prey ratio was 1:3.6. Lugol-fixed samples were collected for cell counts, and observations were carried out under the light microscope at different exposure times $(0.5,1.5,2.5,3.5,4.5,6.5$ and 23.5 or $24.5 \mathrm{~h}$ ) to inspect any deleterious effect on Dinophysis.

\section{Effect on Dinophysis species of exposure to supernatant of Atlantic Fragilidium cf. duplocampanaeforme}

A $15 \mathrm{ml}$ volume of the Atlantic Fragilidium culture in exponential growth (892 cells ml-1) was centrifuged at $3000 \times g$ for $10 \mathrm{~min}$. The obtained supernatant from Fragilidium was added to 24 well culture plates containing $1 \mathrm{ml}$ culture ( 300 cells) of each Dinophysis species (D. acuminata, D. acuta and D. caudata) in triplicate treatments at different supernatant:Dinophysis ratios: 1:1 (T1), 0.5:1 (T2) and 0.1:1 (T3). Light microscopic observations were carried out at different time intervals $(0.5,1.5,2.5,3.5,4.5$ and $23.5 \mathrm{~h})$ to follow any deleterious effect (e.g. cellular death or reduced mobility). Control treatments were done as above but adding $1 \mathrm{ml}$ of culture medium to each Dinophysis species. Lugol-fixed samples were collected for cell counts at the end of the experiment.

\section{Toxin analyses}

Extraction

Samples from feeding experiment cultures (as previously detailed), control cultures of Fragilidium spp. (IO97-01, VGO692 and VGO1120) and monospecific cultures of D. acuminata, D. caudata and D. acuta 
were collected at the end of the exponential growth phase. Control cultures of Dinophysis were grown after the feeding experiments (with the exception of $D$. tripos cultures that were lost).

Cells were filtered through Whatman GF/C glass fiber filters $(1.4 \mu \mathrm{m}, 25 \mathrm{~mm} \varnothing)$ (Whatman), and both filtered cells and culture filtrates were processed for toxin analyses as follows. Cellular toxins were extracted with $\mathrm{MeOH}$, the culture material was sonicated and centrifuged at $5065 \times g$ for $10 \mathrm{~min}$ at $10^{\circ} \mathrm{C}$, the supernatant was removed, and the pellet was extracted again with $\mathrm{MeOH}$ following the same process. Considering that in some feeding experiments, all Dinophysis cell had been eaten, cellular toxin content was referred to as particulate toxin per volume $(\mathrm{ng} \mathrm{ml})^{-1}$ ) of filtered material.

Culture filtrates were loaded onto a Sep-Pak C18 light cartridge. Cartridges were conditioned with $3 \mathrm{ml}$ of $\mathrm{MeOH}$ and equilibrated with $3 \mathrm{ml}$ of Milli-Q water. Subsequently, samples were loaded (volumes ranged from 20 to $45 \mathrm{ml}$ ) and washed with $4 \mathrm{ml}$ of $\mathrm{MeOH}$ : $\mathrm{H}_{2} \mathrm{O}(2: 8)$ to remove salts. Finally, toxins were eluted with $4 \mathrm{ml}$ of $100 \% \mathrm{MeOH}$. Toxin amount was also expressed as $\mathrm{ng} \mathrm{ml}^{-1}$ but in this case referred to as the dissolved (extracellular) toxin concentration.

\section{Analyses by liquid chromatography}

Paralytic shellfish poisoning (PSP) toxins in the Atlantic Fragilidium were analyzed according to Rourke et al. (2008).

\section{Analyses by mass spectrometry}

Particulate and extracellular lipophilic toxinsyessotoxins (YTXs), spirolides (SPXs) and azaspiracids (AZAs) - were analyzed by LC/MS in acidic conditions following the method by Gerssen et al. (2011). LC-MS analyses of DsT were performed on a Thermo Scientific Dionex High-Speed liquid-chromatography (LC) system coupled to an Exactive mass spectrometer (MS), equipped with an Orbitrap mass analyzer and a HESI-II probe for electrospray ionization. The instrument was mass-calibrated daily for positive and negative modes, and the capillary and tube lens voltages were optimized daily, using the automated script within the Exactive acquisition software in both cases. All analyses were performed using the 'balanced' automatic gain control setting with a $50 \mathrm{~ms}$ maximum injection time. Data were acquired using Thermo Scientific Xcalibur 2.1. Opti- mal ion source and interface conditions consisted of a spray voltage of $4 \mathrm{kV}$, sheath gas flow of 30 arbitrary units, auxiliary gas flow of 5 arbitrary units and a capillary temperature of $320^{\circ} \mathrm{C}$.

Toxins were separated on an Acquity BEH C18 column $(2.1 \times 50 \mathrm{~mm}, 1.7 \mu \mathrm{m}$ particle size $)$ maintained at $40^{\circ} \mathrm{C}$ at a flow rate of $300 \mu \mathrm{l} \mathrm{min}{ }^{-1}$. The mobile phase consisted of (A) $2 \mathrm{mM}$ ammonium acetate at $\mathrm{pH} 5.8$ and (B) $100 \% \mathrm{MeOH}$. A linear gradient elution from $10 \%$ to $50 \%$ B was run for $3 \mathrm{~min}, 100 \%$ B was reached at Min 6.5 and held for 3 min before returning to the initial conditions of $10 \% \mathrm{~B}$ in $0.1 \mathrm{~min}$, and this percentage was held until Min 12. Certified reference standard solutions of $\mathrm{OA}$ and dinophysistoxin-2 (DTX2) $\left(\mathrm{m} / \mathrm{z} 805.4779[\mathrm{M}+\mathrm{H}]^{+}, 822.5035\left[\mathrm{M}+\mathrm{NH}_{4}\right]^{+}\right.$ and $827.4592[\mathrm{M}+\mathrm{Na}]^{+}$) and pectenotoxin-2 (PTX2) $\left(876.5148\left[\mathrm{M}+\mathrm{NH}_{4}\right]^{+}\right.$and $\left.881.4696[\mathrm{M}+\mathrm{Na}]^{+}\right)$were purchased from the National Research Council (Canada). A standard working solution containing OA $(0.617 \mathrm{ng}$ $\left.\mathrm{\mu l}^{-1}\right)$, DTX2 $\left(0.266 \mathrm{ng} \mathrm{pl}^{-1}\right)$ and PTX2 $\left(0.573 \mathrm{ng}^{-1}\right)$ in $\mathrm{MeOH}$ was prepared.

\section{RESULTS}

\section{Feeding experiments}

The Atlantic Fragilidium fed heavily upon $D$. acuminata and $D$. caudata (Fig. 3A,B), only occasionally on $D$. tripos and not at all on D. acuta (Fig. 3C,D). The first captured cells of D. acuminata and D. caudata were observed from minutes to a few hours after the initiation of the experiments (see Video S1 in the supplementary information at www.int-res.com/ articles/suppl/a072p241_supp/). The Atlantic Fragilidium did not appear to discriminate between Dinophysis spp. cell sizes (typical vegetative cells and small forms) enumerated in this particular experiment. Both size classes of Dinophysis showed the same trends, and only total abundances are detailed in Fig. 3. Maximum ingestion rates of Dinophysis spp. by Atlantic Fragilidium were observed for $D$. acuminata (Day 1, $I=2.52 \pm 0.48$ [SD] Dinophysis Fragilidium $^{-1} \mathrm{~d}^{-1}$ ) with a prey:predator ratio of $3: 1$, and D. caudata (Day 3, $I=0.58 \pm 0.32$, prey:predator ratio 1:1). These ingestion rates were significantly different ( $t$-test; $\mathrm{n}=3 ; \mathrm{p}<0.005)$. Predation by Atlantic Fragilidium on D. tripos $(I<0.10)$ was confirmed by light microscopic observations, but predation on D. acuta was never observed.

Growth rates and cell densities of Atlantic Fragilidium were larger in the $D$. acuminata and $D$. caudata treatments ( $0.34 \mathrm{~d}^{-1}$ in both cases) relative to those of 


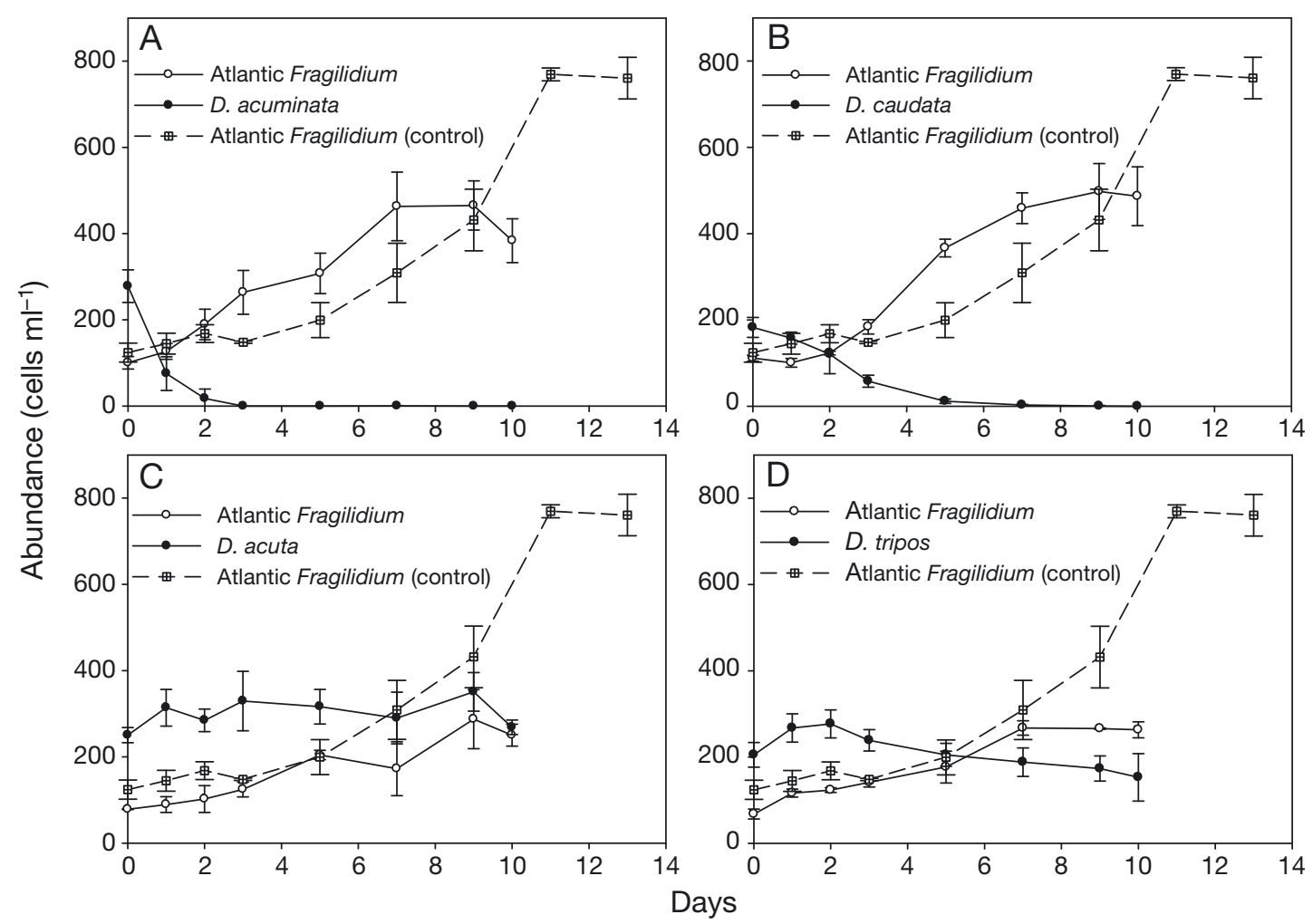

Fig. 3. Abundances (cells ml ${ }^{-1}$ ) of Atlantic Fragilidium cultured with (A) Dinophysis acuminata, (B) D. caudata, (C) D. acuta and (D) D. tripos. Atlantic Fragilidium control treatment abundances for each Dinophysis species are also shown. Error bars are SD

D. acuta and D. tripos $\left(0.22 \mathrm{~d}^{-1}\right.$ and $0.19 \mathrm{~d}^{-1}$, respectively). The Atlantic Fragilidium grew faster when feeding actively on $D$. acuminata and $D$. caudata during the first week of the experiment relative to its control treatment. After that, the cultures reached the stationary phase on Day 9. The Atlantic Fragilidium control showed a lower growth rate $\left(0.17 \mathrm{~d}^{-1}\right)$ but a higher final yield because the stationary phase appeared later (Day 13).

At the end of the experiment, a higher frequency of small Atlantic Fragilidium cells were observed in the D. acuminata $(59.5 \pm 3.9 \%)$ and D. caudata $(49.8 \pm$ $10.6 \%)$ treatments, relative to the controls (34.1 \pm $3.5 \%)$. The average frequency of small Fragilidium cells in each treatment was significantly higher than the control in the case of $D$. acuminata ( $t$-test; $\mathrm{n}=3$; $\mathrm{p}<0.005)$. In contrast, Atlantic Fragilidium cocultured with $D$. acuta and $D$. tripos showed significantly lower proportions of small cells $(19.4 \pm 2.7 \%$ and $14.9 \pm 0.8 \%$, respectively) than in the controls $(t$-test $; \mathrm{n}=3 ; \mathrm{p}<0.005)$. Cell measurements appeared distributed in 2 distinct size classes of small (diameter $[\mathrm{D}]=26.7 \pm 3.8 \mu \mathrm{m}$, length $[\mathrm{L}]=29.5 \pm 3.6 \mu \mathrm{m}, \mathrm{n}=21$ ) and normal vegetative (or planozygote) cells ( $\mathrm{D}=$ $55.5 \pm 5.6 \mu \mathrm{m}, \mathrm{L}=59.6 \pm 7.7 \mu \mathrm{m}, \mathrm{n}=21$ ).
As mentioned above, ingested D. acuta cells were never observed either in the Atlantic Fragilidium or in the Mediterranean Fragilidium and F. subglobossum cultures in this study (Fig. 4). Moreover, we could not find any evidence under the light microscope of grazing by either the Mediterranean Fragilidium or F. subglobosum on any Dinophysis spp. Their control cultures showed similar growth patterns to those of the Atlantic Fragilidium strain, with higher cell densities and growth rates than those mixed with Dinophysis in the second part of the experiment (Days 6 to 11). The only exception was the Mediterranean Fragilidium co-cultured with $D$. acuminata, which reached higher cell densities than the control (Fig. 4).

Cultures of the 3 Dinophysis species (D. acuta, D. tripos and D. caudata) showed cell densities slightly lower but not significantly different from the controls when exposed to the Mediterranean Fragilidium and to F. subglobosum (Fig. 4). Only D. acuminata showed lower densities than in the controls ( $t$-test; $\mathrm{n}=3$; $\mathrm{p}<0.005)$, despite the fact that predation was never observed. Deleterious effects were observed in this case under the light microscope. A high proportion of $D$. acuminata cells were immobile and probably dead by Day 11 when exposed to the Mediterranean 

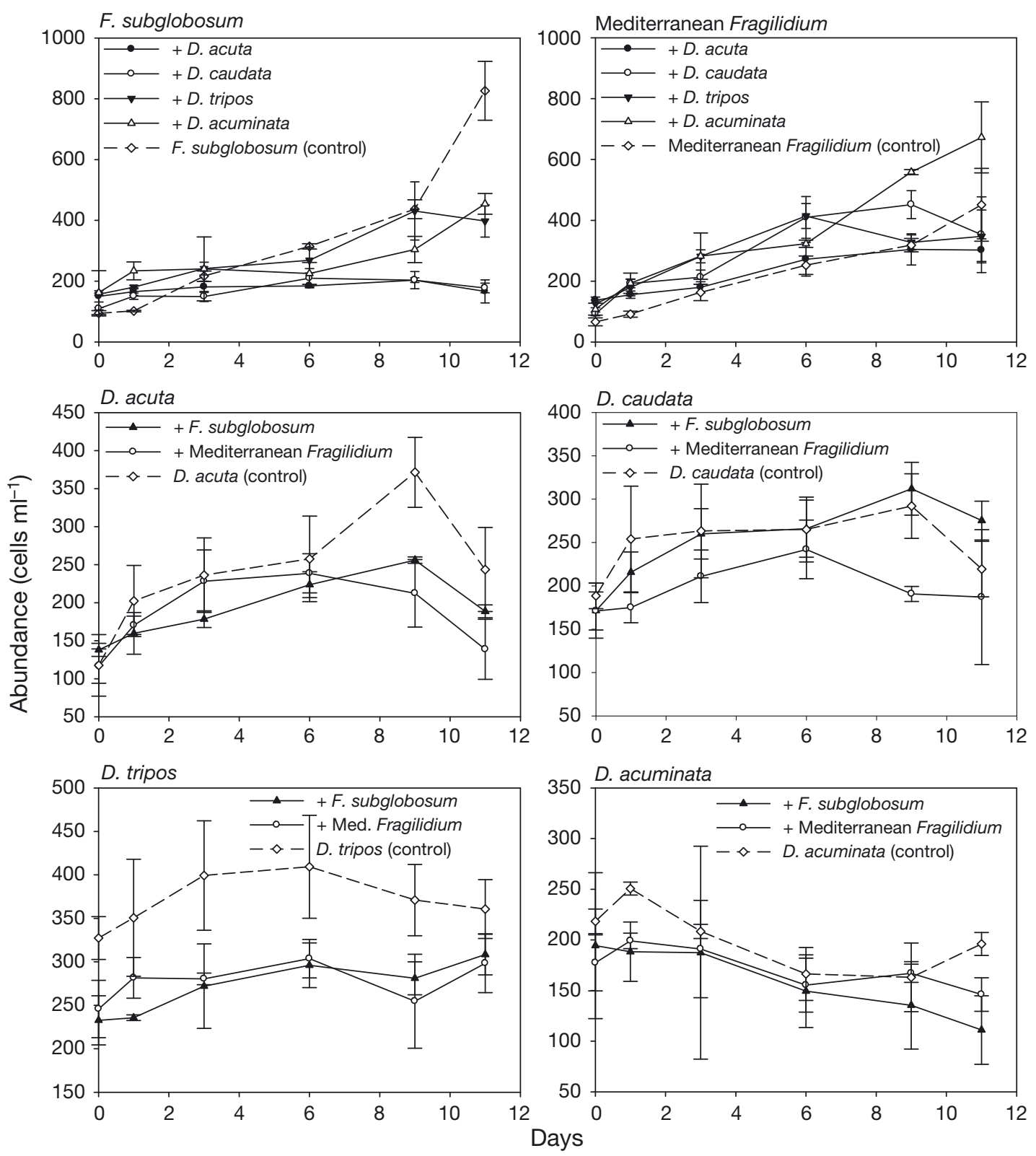

Fig. 4. Abundances (cells $\mathrm{ml}^{-1}$ ) of Dinophysis spp. vs. F. subglobosum and Mediterranean Fragilidium. Upper panels: abundances of F. subglobosum and Mediterranean Fragilidium cultured with 4 Dinophysis spp. and their respective controls. Middle and lower panels: abundances of D. acuta, D. caudata, D. tripos and D. acuminata with both Fragilidium strains and control treatments. Error bars are SD

Fragilidium or to F. subglobosum, in contrast to cells from the control, which displayed normal swimming behavior.

\section{Allelopathy experiments}

Two short-term experiments were conducted to study the potential allelopathic effects of (1) full cultures of the Atlantic Fragilidium and (2) the (cellfree) supernatant of Fragilidium cultures on 3 Dino- physis species $(D$. acuminata, $D$. acuta and $D$. caudata). No allelopathic effects could be observed in either of the 2 treatments. The proportion of immobile cells of each Dinophysis species did not increase significantly when exposed to full cultures of Fragilidium (Fig. 5A-C, Panel 1). In addition, final yields of Dinophysis species exposed to full cultures of Atlantic Fragilidium were similar to the controls (Fig. 5, Panel 2). Likewise, the proportion of nonmotile cells of Dinophysis species did not increase significantly when exposed to different volume ratios 


\section{A) Dinophysis acuminata}
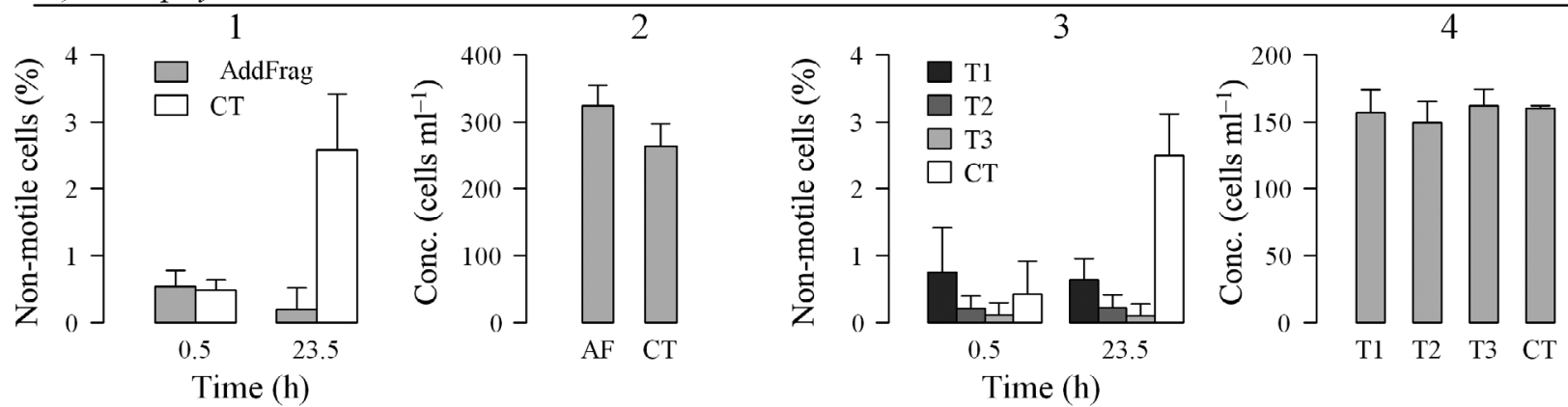

B) Dinophysis acuta
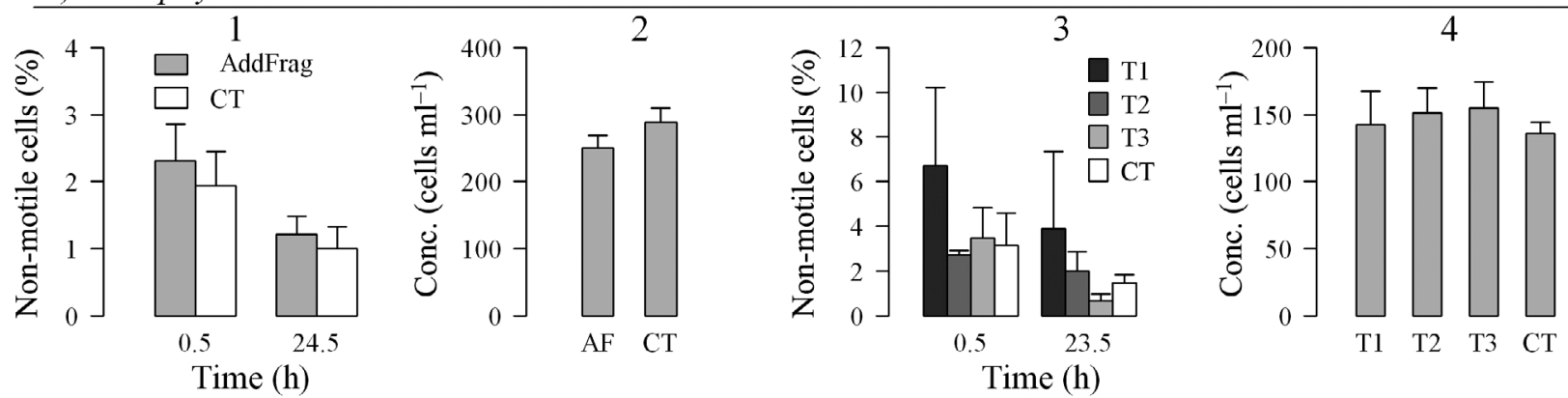

C) Dinophysis caudata
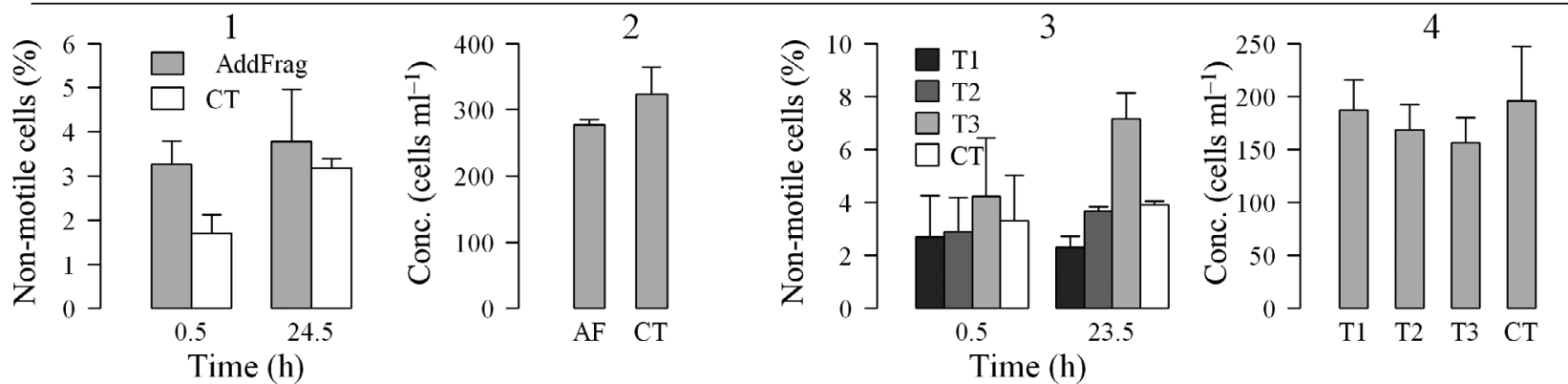

Fig. 5. Results from the allelopathic experiments for (A) Dinophysis acuminata, (B) D. acuta and (C) D. caudata. Panels 1 and 2: Experiment with full cultures of Atlantic Fragilidium - (1) \% of non-motile cells of Dinophysis spp. at different times after adding full cultures of Atlantic Fragilidium, and (2) final concentration of Dinophysis spp. (AF: Dinophysis spp. with Atlantic Fragilidium; CT: control). Panels 3 and 4: Experiment with supernatant of Fragilidium-(3) \% of non-motile cells of Dinophysis spp. (cells ml ${ }^{-1}$ ) at different exposure times with different volume ratios of Fragilidium supernatant:Dinophysis (1:1 [T1], 0.5:1 [T2] and 0.1:1 [T3], CT: control), and (4) final concentration of Dinophysis spp. Error bars are SD

of the supernatant (T1, T2 and T3, see methods and legend in Fig. 5) of the Atlantic Fragilidium cultures (Fig. 5, Panel 3), and the final yield of the 3 Dinophysis species was similar in supernatant treatments relative to the controls (Fig. 5, Panel 4).

The only deleterious effect that could be seen at the end of both allelopathic experiments was a slower swimming speed in D. caudata.

\section{Toxin analyses}

PSP toxins, YTXs, SPXs and AZAs were not detected either in Dinophysis or in Fragilidium species. More- over, DsT were not found in any of the control cultures of the 3 Fragilidium strains used here.

In this study, we focused our analyses in the detection and quantification of DsT in the Atlantic Fragilidium plus Dinophysis cells (particulate toxins) and in the culture filtrates. Monospecific cultures of $D$. acuminata and $D$. acuta showed the same toxin profiles (intracellular and extracellular; Fig. 6) as those in the feeding experiments: OA in D. acuminata, and OA, DTX2 and PTX2 in D. acuta. However, in the case of D. caudata, 3 different toxins (OA, DTX2 and PTX2) were found in the filtrate, whereas only PTX2 was found in the cells. Toxin analyses of $D$. tripos could not be performed, and PTX2 was the only com- 


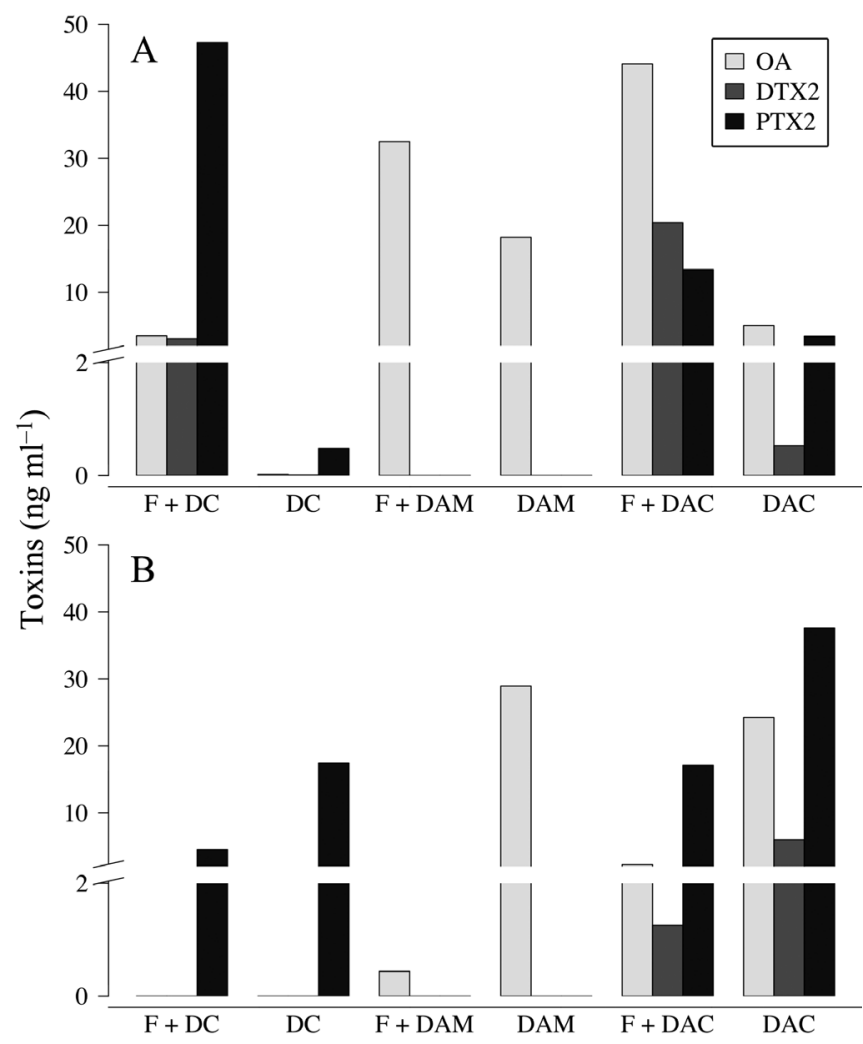

Fig. 6. Comparison of Dinophysis toxins (OA, DTX2, PTX2) between (A) culture filtrate and (B) particulate matter in the predation experiments (Dinophysis + Atlantic Fragilidium) and monospecific Dinophysis cultures. F+DC: Fragilidium + Dinophysis caudata, DC: Dinophysis caudata, F+DAM: Fragilidium + Dinophysis acuminata, DAM: Dinophysis acuminata, F+DAC: Fragilidium + Dinophysis acuta, DAC: Dinophysis acuta

pound detected in the mixed cultures with Atlantic Fragilidium. Quantitative results, expressed in $\mathrm{ng} \mathrm{ml}^{-1}$, revealed differences in the amount of OA, DTX2 and PTX2 between the monospecific Dinophysis cultures and those incubated with Atlantic Fragilidium (Fig. 6). The content of DsT in the particulate fraction was always higher in the monospecific Dinophysis cultures than in those from the feeding experiments with Fragilidium.

Conversely, estimations of extracellular toxins showed higher levels in the culture filtrates from the feeding experiments than in those from monospecific Dinophysis cultures (Fig. 6). For example, estimates of particulate PTX2 in D. caudata cultures were 17.5 $\mathrm{ng} \mathrm{ml}{ }^{-1}$ in the monospecific culture and $4.5 \mathrm{ng} \mathrm{ml}^{-1}$ in the culture with Fragilidium. This pattern was even more pronounced in the case of $D$. acuminata (28.9 vs. $0.4 \mathrm{ng} \mathrm{OA} \mathrm{ml}^{-1}$ ) and D. acuta (24.2 vs. $2.3 \mathrm{ng} \mathrm{OA}$ $\mathrm{ml}^{-1} ; 6.0$ vs. $1.3 \mathrm{ng}$ DTX2 $\mathrm{ml}^{-1}$ and 37.6 vs. $17.1 \mathrm{ng}$ PTX2 $\mathrm{ml}^{-1}$ ).

\section{DISCUSSION}

\section{Mixotrophy and growth in Fragilidium}

Hansen (2011) described 2 types of growth response in mixotrophic dinoflagellates as a function of prey concentration. According to this author, Fragilidium belongs to 'Type 2' species (together with Dinophysis acuminata, Karlodinium armiger and Paragymnodinium shiwaense), which require high prey concentrations to attain maximum growth rates. Food uptake in 'Type 2' mixotrophs significantly increases the growth rate at low irradiances and only increases the growth rate in some cases when light is not a limiting factor. Some 'Type 2' species grow relatively fast at high irradiances without food (as is the case for Fragilidium), while other species grow slowly at high irradiances without food ( $K$. armiger; Berge et al. 2008). In our case, we observed that food uptake ( $D$. acuminata and D. caudata) in Atlantic Fragilidium accelerated its growth during the exponential phase, but stationary phase was reached sooner than in the Fragilidium controls, which attained higher final yields.

Differences in growth rates between purely autotrophic or mixotrophic cultures of Fragilidium have been reported before for $F$. subglobosum (Skovgaard 1996). Skovgaard (1996) showed that F. subglobosum growth was significantly enhanced in mixotrophic cultures at low irradiance $\left(<100 \mu \mathrm{E} \mathrm{m}^{-2} \mathrm{~s}^{-1}\right)$, while small differences between mixotrophic and autotrophic cultures were found in high light conditions. Therefore, the light intensity used in our study $\left(150 \mu \mathrm{E} \mathrm{m} \mathrm{m}^{-2} \mathrm{~s}^{-1}\right)$ might render minor differences in autotrophic vs. mixotrophic growth rates, but the influence of variable light conditions was not tested in our feeding experiments.

The higher growth rates achieved in mixotrophic cultures of Atlantic Fragilidium feeding on D. acuminata and D. caudata coincided with the formation of a larger proportion of small cells of Fragilidium that did not undergo further cell division, leading to the onset of the stationary phase earlier than in the controls. Feeding of these small cells on Dinophysis was never observed. These small Fragilidium cells have been claimed to be gametes, they display a slightly different plate arrangement (Amorim et al. 2013), and apparently they do not revert to the vegetative condition. The dimensions of small cells in the Atlantic Fragilidium fit within the range shown by Amorim et al. (2013) in their Portuguese isolate of $F$. cf. duplocampanaeforme and by Nézan \& Chomérat (2009) in natural assemblages of $F$. duplocampanaeforme (26 
to $28 \mu \mathrm{m})$. If these small cells were gametes, their formation could be argued to be the reason for the lower final yields in most feeding experiments relative to the controls. However, considering that higher final yields were achieved in every Fragilidium control vs. those observed in cultures with Dinophysis, we should look for alternative explanations, such as nutrient resource competition between the predator and its dinoflagellate prey or some allelopathic effects caused by Dinophysis spp. (or its toxins) on Fragilidium. It is likely that the different culture volumes used in the feeding experiments could have also influenced the final cell densities in $50 \mathrm{ml}$ flasks vs. 24 microwell plates, but not the observed feeding behavior and selectivity on Dinophysis.

In summary, Dinophysis stimulated the short-term growth of Fragilidium but also the production of a higher proportion of small cells in laboratory cultures whenever the prey was available. Nevertheless, we should be cautious about extrapolation of these observations in culture conditions to the field. The onset of dense populations of Fragilidium would following Dinophysis proliferations has never been observed in the Galician Rías, despite the endemic occurrence of Dinophysis in the region. During a cruise in the northeastern Bay of Biscay, France, in July 2006, observations of abundant ecdysal cysts of F. subglobosum in the microphytoplankton fraction coincided with a decline of a preceding $D$. acuminata bloom (Velo-Suarez et al. 2010). Nevertheless, ingestion of D. acuminata (observations in fixed plankton samples) was only confirmed in specimens of $F$. duplocampanaeforme, a species present in a much lower proportion than was first described from this cruise data (Nézan \& Chomérat 2009). These observations are in agreement with our experimental results.

\section{Grazing impact of Fragilidium and prey (Dinophysis) specificity}

Grazing impact studies of mixotrophic dinoflagellates are scarce (Hansen 2011). In the case of Fragilidium subglobosum, grazing rates on Ceratium lineatum ranged from 2.1 to 5.8 cells Fragilidium ${ }^{-1} \mathrm{~d}^{-1}$ depending on light conditions (Skovgaard 1996). Our estimated maximum of 2.2 cells of $D$. acuminata per day ingested by the Atlantic Fragilidium is at the lower limit of this range, but the lowest ingestion rates in F. subglobosum were determined at irradiances higher than $\sim 120 \mu \mathrm{E} \mathrm{m}^{-2} \mathrm{~s}^{-1}$, with a peak at 63 to $107 \mu \mathrm{E} \mathrm{m}^{-2} \mathrm{~s}^{-1}$. Grazing impact on D. acuminata in the laboratory cannot be directly extrapolated to the field. However, if we considered a theoretical example in which equally dense patches of predator and prey, no cell losses and maximum grazing rates on $D$. acuminata were observed, an initial population of $10^{3}$ cells $1^{-1}$ of $F$. cf. duplocampanaeforme could totally clear out a proliferation of $D$. acuminata of $10^{4}$ cells $\mathrm{l}^{-1}$ in $\sim 5 \mathrm{~d}$. Thus, even if it has not been demonstrated yet, the ability of Fragilidium to remove significant densities of $D$. acuminata (and to a lesser extent $D$. caudata) in the field should be taken into account. Moreover, the predation of F. duplocampanaeforme on $D$. acuminata but not on $D$. acuta could play some role in the population dynamics of these species in late summer-autumn in the Galician coasts, when $D$. acuminata is progressively replaced by $D$. acuta. In this regard, during microscopic examination of samples from a widespread bloom of Dinophysis in the Galician Rías (October 2013), 1 Fragilidium specimen was observed that had recently ingested $D$. acuminata, but there was not any observation of Fragilidium recently fed on $D$. acuta despite the overwhelming dominance of the latter over D. acuminata (F. Rodríguez unpubl. data).

In an earlier study, Park \& Kim (2010) showed the specific predation of $F$. duplocampanaeforme on several Dinophysis species. Some of these, like D. acuminata and $D$. caudata, were included in the present study, and our Atlantic Fragilidium also fed upon them. In addition, these authors observed feeding on $D$. infundibula, whereas $D$. fortii was not ingested, demonstrating the existence of prey selectivity within Korean Fragilidium and Dinophysis strains. In this sense, we observed that $D$. acuta was ignored by the Atlantic Fragilidium and D. tripos was rarely ingested. LSUrDNA analyses of several Portuguese $F$. cf. duplocampanaeforme isolates and the $2 F$. cf. duplocampanaeforme strains included in our study (Amorim et al. 2013) clustered them together. Although we did not test the predation of our Fragilidium isolates on dinoflagellate genera other than Dinophysis, the ingestion of Ceratium horridum by a Portuguese isolate of $F$. cf. duplocampanaeforme indicates that this species may prey on other dinoflagellate genera in addition to Dinophysis. Park \& Kim (2010) showed that their Fragilidium duplocampanaeforme did not ingest Ceratium furca, but given the selectivity observed toward certain Dinophysis species, it would not be surprising that it could ingest other Ceratium spp.

Selective feeding experiments using artificial particles showed that predatory dinoflagellates such as Oxyrrhis marina select their prey according to its 
size, biochemical composition or cell surface charge (Roberts et al. 2011b). Size itself does not explain the selectivity toward certain Dinophysis species because, for example, $D$. acuta has a similar or smaller size than $D$. caudata or $D$. tripos and could be easily engulfed by Fragilidium. Rather, it seems that some kind of recognition mechanism could regulate this differential feeding on certain Dinophysis species. Lectins and carbohydrate-binding proteins have been shown to play a role as phagocytic receptors in protists (Roberts et al. 2006), and these could be part of the recognition mechanism used by Fragilidium. This hypothesis needs to be verified by further studies on the cell surface carbohydrate characterization of Dinophysis species (Raho et al. in press). Regarding the inability of $F$. subglobosum to ingest Dinophysis, there is no information available testing this hypothesis except the observations from the Bay of Biscay reported above.

\section{Influence of local adaptations and toxins on Dinophysis predation by Fragilidium}

In the case of the Mediterranean F. cf. duplocampanaeforme, it could first be hypothesized that this isolate does not consider Dinophysis among its potential prey or secondly, and more suggestively, that some type of local adaptation restrains its feeding on Dinophysis originating from the same region. This theory cannot be tested by other means than by feeding experiments including Mediterranean cultures or isolated cells of Dinophysis. If the second hypothesis were true, that would suggest some co-evolution of predator and prey within an 'arms race' that seems difficult to be found in planktonic organisms (Roberts et al. 2011a). Indeed, this has been suggested to be the case in some highly specific predator-prey relationships, such as those occurring between protist parasites and their hosts (Figueroa et al. 2010). In marine mixotrophic dinoflagellates exhibiting a certain level of prey specificity, such as Fragilidium, that hypothesis could not be totally discarded in favor of general chemical interactions expected in planktonic systems.

Differences in intracellular toxin content for each Dinophysis strain do not seem to explain different feeding efficiency and selectivity by Fragilidium. Nevertheless, the toxic nature of the prey has been suggested to affect in some way the grazing selectivity of Fragilidium cf. mexicanum (Jeong et al. 1999). Microalgal toxins are known to produce a variety of allelopathic effects to outcompete other organisms and act as a defense against protistan grazers or to cause cell immobilization before capturing other protists or even metazoan prey (Fistarol et al. 2003, Skovgaard \& Hansen 2003, Granéli \& Hansen 2006, Sheng et al. 2010, Berge et al. 2012, Blossom et al. 2012). In the case of Fragilidium, no PSP or lipophylic toxic compounds have been found in earlier studies or in the present study, but reduced mobility of some of its prey suggests other chemical cues involved in that process. In this sense, protein kinase and G-protein inhibitors have been shown to decrease the motile response and ingestion in a marine ciliate (Uronema sp.) and in the dinoflagellate Oxyrrhis marina (Hartz et al. 2008). In the present case, it would be the predator that would benefit from these chemical interactions to facilitate the capture of its prey.

Toxin profiles in Dinophysis controls coincided with those from the feeding experiments, and the discrepancies observed between the filtered cells and the culture filtrates in the case of $D$. caudata were likely due to detection of a very low biomass in the cells fraction because OA and DTX2 represented a very small percentage of the total toxin content of this species. In the case of $D$. tripos, although we could not include analyses from a monospecific culture, the detection of PTX2 in mixed cultures with Fragilidium matched the toxin profile observed for this strain in a previous study (Rodríguez et al. 2012). Overall, toxin analyses indicated that Fragilidium did not promote any metabolic transformations of the DsT, in contrast to those found in filter-feeding bivalves that accumulate lipophylic toxins (i.e. secoacid derivatives of pectenotoxins in blue mussels; Vale \& Sampayo 2002, Miles et al. 2006, Wilkins et al. 2006, Pizarro et al. 2013). However, quantitative results in the feeding experiments showed that Fragilidium presence was accompanied by a larger proportion of toxins in the extracellular fraction. A possible explanation for this result could be that Dinophysis cells release these toxins, although we could only speculate about the possible mechanisms (defense or deterrent mechanism, physical stress or 'sloppy feeding' during Fragilidium engulfment of Dinophysis, death processes, etc.). The defensive role of dinoflagellate toxins has been strengthened in the case of paralytic shellfish toxin-producers, such as species of the genus Alexandrium (Hansen 1989, Bagoien et al. 1996). However, in the case of OA-producing species, Sugg \& VanDolah (1999) found that Prorocentrum lima had allelopathic effects (growth inhibition) on other dinoflagellates, but compounds other than OA were mainly responsible for these effects. 


\section{CONCLUSIONS}

The Atlantic Fragilidium cf. duplocampanaeforme was the only strain able to feed on Dinophysis spp. from the Galician Rías, with different grazing efficiencies on $D$. acuminata, $D$. caudata and $D$. tripos. It did not ingest $D$. acuta. Our experiments using 2 strains of F. duplocampanaeforme and 1 of F. subglobosum showed that prey specificity of the mixotrophic dinoflagellate Fragilidium on Dinophysis is very different between different species from a similar area (F. subglobosum vs. Atlantic F. cf. duplocampanaeforme) and between different geographical isolates of the same species (Atlantic and Mediterranean $F$. cf. duplocampanaeforme). These inter- and intraspecific differences highlight the complexity of predator-prey interactions in mixotrophic dinoflagellates like Fragilidium, which display some specific traits that are not likely to be dependent on the prey size but rather depend on the chemical detection of its prey. Further studies are needed to evaluate the existence of local adaptations in the predator, suggested by the inability of the Mediterranean strain of F. cf. duplocampanaeforme to graze on Atlantic Dinophysis strains, and to find out whether isolates exist that are unable to feed on Dinophysis from the same area or whether there is some specific predator/prey relationship between $F$. cf. duplocampanaeforme and Dinophysis. No metabolic transformations of DsT could be attributed to the Atlantic F. cf. duplocampanaeforme. However, quantitative differences between particulate and extracellular toxin contents between the monospecific Dinophysis cultures and feeding experiments point to the possibility that Fragilidium promotes a higher release of toxins from Dinophysis cells, but the exact mechanism (i.e. cellular stress before or during predation, excretion from Fragilidium, etc.) is unknown.

Acknowledgements. We thank Drs. Ana Gago and José M. Leao (University of Vigo) for their help in LC-MS toxin analyses of YTXs, SPXs, and AZAs. We also thank Patricio Díaz for his assistance with graphs. This study was supported by MICINN (DIGEDINO Project CTM2009-12988C02-01/MAR).

\section{LITERATURE CITED}

Amorim A, Veloso V, Rodríguez F, Fraga S (2013) Life cycle, morphology and phylogeny of species of Fragilidium Balech from west Iberia. In: Marret F, Lewis JM, Bradley LR (eds) Biological and geological perspectives of dinoflagellates. Geological Society, London, p 223-232

Bagoien E, Miranda A, Reguera B, Franco JM (1996) Effects of two paralytic shellfish toxin producing dinoflagellates on the pelagic harpacticoid copepod Euterpina acutifrons. Mar Biol 126:361-369

Balech E (1959) Two new genera of dinoflagellates from California. Biol Bull 116:195-203

Balech E (1987) Una especie nueva del género Fragilidium (Dinoflagellata) de la Bahía de Chamela, Jalisco, México. Anales del Instituto de Biología. Universidad Nacional Autónoma Mexicana 58:479-486

Balech E (1990) Four new dinoflagellates. Helgol Meeresunters 44:387-396

Berge T, Hansen P, Moestrup Ø (2008) Feeding mechanism, prey specificity and growth in light and dark of the plastidic dinoflagellate Karlodinium armiger. Aquat Microb Ecol 50:279-288

> Berge T, Poulsen LK, Moldrup M, Daugbjerg N, Hansen PJ (2012) Marine microalgae attack and feed on metazoans. ISME J 6:1926-1936

Blossom HE, Daugbjerg N, Hansen PJ (2012) Toxic mucus traps: a novel mechanism that mediates prey uptake in the mixotrophic dinoflagellate Alexandrium pseudogonyaulax. Harmful Algae 17:40-53

Figueroa RI, Garcés E, Camp J (2010) Reproductive plasticity and local adaptation in the host-parasite system formed by the toxic Alexandrium minutum and the dinoflagellate parasite Parvilucifera sinerae. Harmful Algae 10:56-63

Fistarol GO, Legrand C, Granéli E (2003) Allelopathic effect of Prymnesium parvum on a natural plankton community. Mar Ecol Prog Ser 255:115-125

Frost BW (1972) Effects of size and concentration of food particles on feeding behavior of marine planktonic copepod Calanus pacificus. Limnol Oceanogr 17:805-815

Gerssen A, Mulder P, de Boer J (2011) Screening of lipophilic marine toxins in shellfish and algae: development of a library using liquid chromatography coupled to orbitrap mass spectrometry. Anal Chim Acta 685:176-185

Granéli E, Hansen PJ (2006) Allelopathy in harmful algae: a mechanism to compete for resources? In: Granéli E, Turner JT (eds) Ecology of harmful algae. SpringerVerlag, Heidelberg, p 189-201

Hansen PJ (1989) The red tide dinoflagellate Alexandrium tamarense: effects on behaviour and growth of a tintinnid ciliate. Mar Ecol Prog Ser 53:105-116

> Hansen PJ (2011) The role of photosynthesis and food uptake for the growth of marine mixotrophic dinoflagellates. J Eukaryot Microbiol 58:203-214

> Hansen PJ, Nielsen TG (1997) Mixotrophic feeding of Fragilidium subglobosum (Dinophyceae) on three species of Ceratium: effects of prey concentration, prey species and light intensity. Mar Ecol Prog Ser 147:187-196

> Hartz AJ, Sherr BF, Sherr EB (2008) Using inhibitors to investigate the involvement of cell signaling in predation by marine phagotrophic protists. J Eukaryot Microbiol 55: $18-21$

Jakobsen HH, Hansen PJ, Larsen J (2000) Growth and grazing responses of two chloroplast-retaining dinoflagellates: effect of irradiance and prey species. Mar Ecol Prog Ser 201:121-128

> Jeong HJ, Shim JH, Kim JS, Park JY, Lee CW, Lee Y (1999) Feeding by the mixotrophic thecate dinoflagellate Fragilidium $\mathrm{cf}$. mexicanum on red-tide and toxic dinoflagellates. Mar Ecol Prog Ser 176:263-277

> Jeong HJ, Yoo YD, Park JY, Song JY and others (2005) Feeding by phototrophic red-tide dinoflagellates: five species newly revealed and six species previously known to be mixotrophic. Aquat Microb Ecol 40:133-150 
Lindemann E (1924) Peridineen aus dem goldenen Horn und dem Bosporus. Bot Arch 5:216-233

Miles CO, Wilkins AL, Munday JS, Munday R and others (2006) Production of 7-epi-pectenotoxin-2 seco acid and assessment of its acute toxicity to mice. J Agric Food Chem 54:1530-1534

> Nézan E, Chomérat N (2009) Fragilidium duplocampanaeforme sp nov (Dinophyceae): a new phagotrophic dinoflagellate from the French Atlantic coast. Eur J Protistol 45:2-12

Park MG, Kim M (2010) Prey specificity and feeding of the thecate mixotrophic dinoflagellate Fragilidium duplocampanaeforme. J Phycol 46:424-432

Park MG, Kim S, Kim HS, Myung G, Kang YG, Yih W (2006) First successful culture of the marine dinoflagellate Dinophysis acuminata. Aquat Microb Ecol 45:101-106

Pizarro G, Moroño A, Paz B, Franco JM, Pazos Y, Reguera B (2013) Evaluation of passive samplers as a monitoring tool for early warning of Dinophysis toxins in shellfish. Mar Drugs 11:3823-3845

Raho N, Jaén D, Rodríguez F, Reguera B, Mamán L (in press) Identification of carbohydrates binding to FITC-conjugated lectins during the life cycle in different species of Dinophysis genus. In: Kim H-G (ed) XVth International conference on harmful algae. National Fisheries Research \& Development Institute, Gyeongnam (2012)

> Reguera B, Velo-Suarez L, Raine R, Park MG (2012) Harmful Dinophysis species: a review. Harmful Algae 14:87-106

Reguera B, Riobó P, Rodríguez F, Díaz P and others (2014) Dinophysis toxins: causative organisms, distribution and fate in shellfish. Mar Drugs 12:394-461

Roberts EC, Zubkov MV, Martin-Cereceda M, Novarino G, Wootton EC (2006) Cell surface lectin-binding glycoconjugates on marine planktonic protists. FEMS Microbiol Lett 265:202-207

Roberts EC, Legrand C, Steinke M, Wootton EC (2011a) Mechanisms underlying chemical interactions between predatory planktonic protists and their prey. J Plankton Res 33:833-841

Roberts EC, Wootton EC, Davidson K, Jeong HJ, Lowe CD, Montagnes DJS (2011b) Feeding in the dinoflagellate

Editorial responsibility: Robert Sanders,

Philaldelphia, USA
Oxyrrhis marina: linking behaviour with mechanisms. J Plankton Res 33:603-614

Rodríguez F, Escalera L, Reguera B, Rial P, Riobó P, da Silva T (2012) Morphological variability, toxinology and genetics of the dinoflagellate Dinophysis tripos (Dinophysiaceae, Dinophysiales). Harmful Algae 13:26-33

> Rourke WA, Murphy CJ, Pitcher G, van de Riet JM, Burns BG, Thomas KM, Quilliam MA (2008) Rapid postcolumn methodology for determination of paralytic shellfish toxins in shellfish tissue. J AOAC Int 91:589-597

Sheng J, Malkiel E, Katz J, Adolf JE, Place AR (2010) A dinoflagellate exploits toxins to immobilize prey prior to ingestion. Proc Natl Acad Sci USA 107:2082-2087

Skovgaard A (1996) Engulfment of Ceratium spp. (Dinophyceae) by the thecate photosynthetic dinoflagellate Fragilidium subglobosum. Phycologia 35:490-499

Skovgaard A, Hansen PJ (2003) Food uptake in the harmful alga Prymnesium parvum mediated by excreted toxins. Limnol Oceanogr 48:1161-1166

> Stoecker DK (1999) Mixotrophy among dinoflagellates. J Eukaryot Microbiol 46:397-401

Stoecker D, Tillmann U, Granéli E (2006) Phagotrophy in harmful algae. In: Granéli E, Turner JT (eds) Ecology of harmful algae, Book 189. Springer, Heidelberg, p 177-187

> Sugg LM, VanDolah FM (1999) No evidence for an allelopathic role of okadaic acid among ciguatera-associated dinoflagellates. J Phycol 35:93-103

> Vale P, Sampayo MA (2002) Pectonotoxin-2 seco acid, 7-epipectenotoxin-2 seco acid and pectonotoxin-2 in shellfish and plankton from Portugal. Toxicon 40:979-987

> Velo-Suarez L, Reguera B, Gonzalez-Gil S, Lunven M, Lazure P, Nezan E, Gentien P (2010) Application of a 3D Lagrangian model to explain the decline of a Dinophysis acuminata bloom in the Bay of Biscay. J Mar Syst 83: 242-252

von Stoch HA (1969) Dinoflagellaten aus der Nordsee II. Helgol Wiss Meeresunters 19:569-577

> Wilkins AL, Rehmann N, Torgersen T, Rundberget $\mathrm{T}$ and others (2006) Identification of fatty acid esters of pectenotoxin-2 seco acid in blue mussels (Mytilus edulis) from Ireland. J Agric Food Chem 54:5672-5678

Submitted: January 28, 2014; Accepted: April 14, 2014

Proofs received from author(s): May 19, 2014 